\title{
Pathological Basis of Primary Heart Block
}

\author{
MICHAEL DAVIES ${ }^{\star}$ AND ALAN HARRIS \\ From the Departments of Pathology and Cardiology, St. George's Hospital, London S.W.1
}

The cause of chronic complete heart block is often obscure but was formerly assumed, in many cases, to be ischaemic in origin (Penton, Miller, and Levine, 1956). In recent years it has become apparent that coronary artery disease is a relatively uncommon cause of chronic heart block, and the terms, "isolated disease of the conduction system" (Portal et al., 1962) or "primary heart block" (Zoob and Smith, 1963) have been introduced for those patients with complete heart block, and no obvious cause. In a necropsy series at this hospital of 65 consecutive patients dying with chronic heart block, 26 were found to have bilateral bundlebranch fibrosis (Harris et al., 1969). The pathology of bundle-branch fibrosis has not been described in detail and the morphological findings in 27 cases are therefore presented in this paper.

\section{SUBJECTS AND METHODS}

All 27 patients had presented with chronic heart block, most with Adams-Stokes attacks. The coronary arteries were studied by post-mortem angiography (Crawford, Dexter, and Teare, 1961). In addition to detailed histological study of the whole heart, the conduction system was studied by a serial section technique (Davies, 1967). A series of $\mathbf{4 0}$ control hearts from subjects in the same age range with normal electrocardiograms recorded within 3 months of death was studied by identical means.

\section{Results}

The anatomy of the right branch is very different from that of the left. The right is a single discrete muscle bundle in direct continuation with the main bundle of His, and only breaks up into smaller branches peripherally at the inferior margin of the interventricular septum. The left is not a single

\footnotetext{
Received Augúst 28, 1968.

* In receipt of the William Shepherd Research Fellowship from the board of governors St. George's Hospital.
}

branch, though clinical terminology may imply this. It is a series of radiating fine branches arising directly from the main bundle over a considerable distance (Fig. 1).

The morphology of the conduction system in bundle-branch fibrosis clearly contrasts with that in control hearts. With increasing age, control hearts do show progressive loss of conduction fibres in the origin of the left branches, associated with ageing changes and calcification in the collagen of the upper interventricular septum. Since the left branch consists of multiple fine fascicles, many may be lost without producing conduction defects, and up to 50 per cent have been observed to be destroyed without electrocardiographic abnormality. The discrete right bundle-branch shows increasing fibrosis with age but no significant conduction fibre loss. Fine fibrosis throughout the conduction system increases with age, but in normal subjects only in the origins of the left branches is appreciable conduction fibre loss seen. It thus follows that in studying the conduction system isolated histological sections of the left branch origins can give a misleading picture.

The morphological changes in the conduction system from cases of bundle-branch fibrosis fall into 3 groups. In type $A$ loss of conduction fibres is maximal in the origin and upper third of the left branch, and the intramyocardial middle third of the right branch (Fig. 1). Such loss is associated with collapse and fibrosis in the bundle-branches (Fig. 2-5).

In type B (Fig. 1) changes in the origin of the left branch extend into the adjacent main bundle. The connective tissue outline of the branch and main bundle is preserved (Fig. 6), but conduction fibres are absent.

In type $\mathrm{C}$ (Fig. 1) the more distal bundlebranches and peripheral conduction network in both ventricles are maximally affected.

The description of lesions in the conduction sys219 


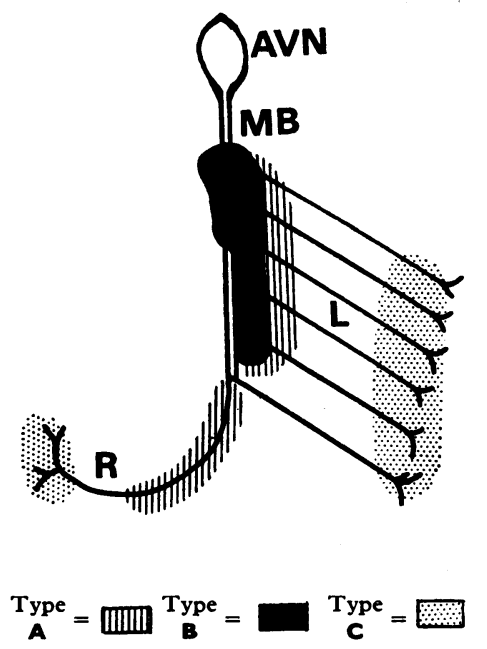

FIG. 1.-A diagrammatic representation of the conduction system emphasizing the different anatomy of the right $(R)$ and left $(L)$ bundle-branches. The areas affected in different types of bundle-branch fibrosis are shown. AVN, AV node; $\mathrm{MB}$, main bundle.

mum damage. Cases purely of one type are rare. Type $\mathrm{C}$ bundle-branch fibrosis is always associated with some loss of proximal left bundle-branches. In all cases the AV node and proximal main bundle are normal.

Some patients show different stages of development of fibrotic areas within the bundle-branches, suggesting that active loss of conduction fibres is still occurring at the time of death. The initial change is vacuolation of the conduction fibre, with fusion of myofibrils into a hyaline mass (Fig. 7). Small round cells with deeply basophilic cytoplasm appear within the sarcoplasmic sheath (Fig. 8). After loss of conduction fibres in this active phase, the outline of the bundle-branch collapses and is replaced by fine fibrosis (Fig. 8 and 9). The characteristic feature of bundle-branch fibrosis, in contrast with cardiomyopathies, is the normality in histological appearances of immediately adjacent contractile myocardium.

The degree of cardiac hypertrophy as indicated by total heart weight is considerable (Table). Diffuse and focal endocardial thickening occurs in both ventricles. Diffuse myocardial scarring was increased in all patients with bundle-branch fibrosis as compared with control cases, but such scarring is predominantly interstitial and remote from the

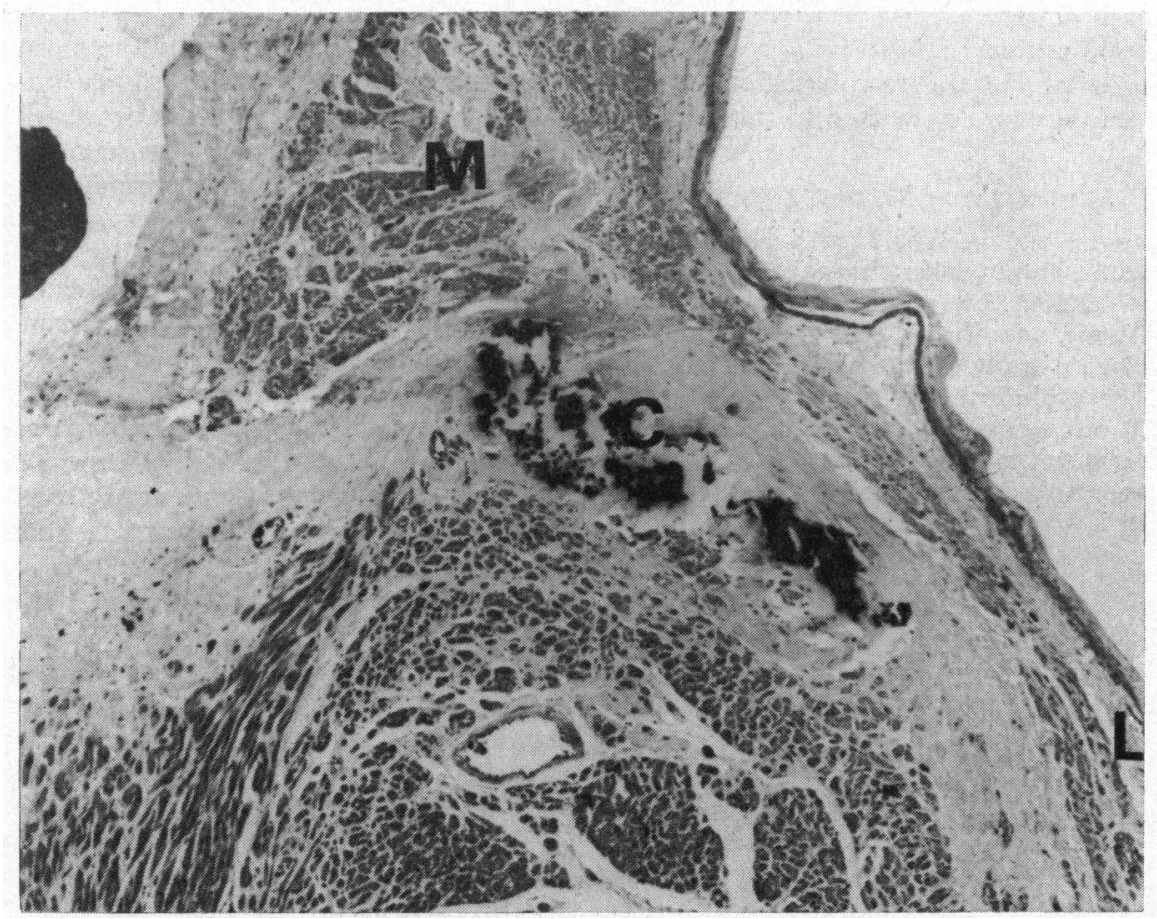

FIG. 2.-The normal origin of one of the left bundle-branches (L) from the main bundle (M). Calcification (C), occurring as a normal ageing change in the upper interventricular septum, lies in close proximity to the conduction system. (H. and E. $\times 40$.) 


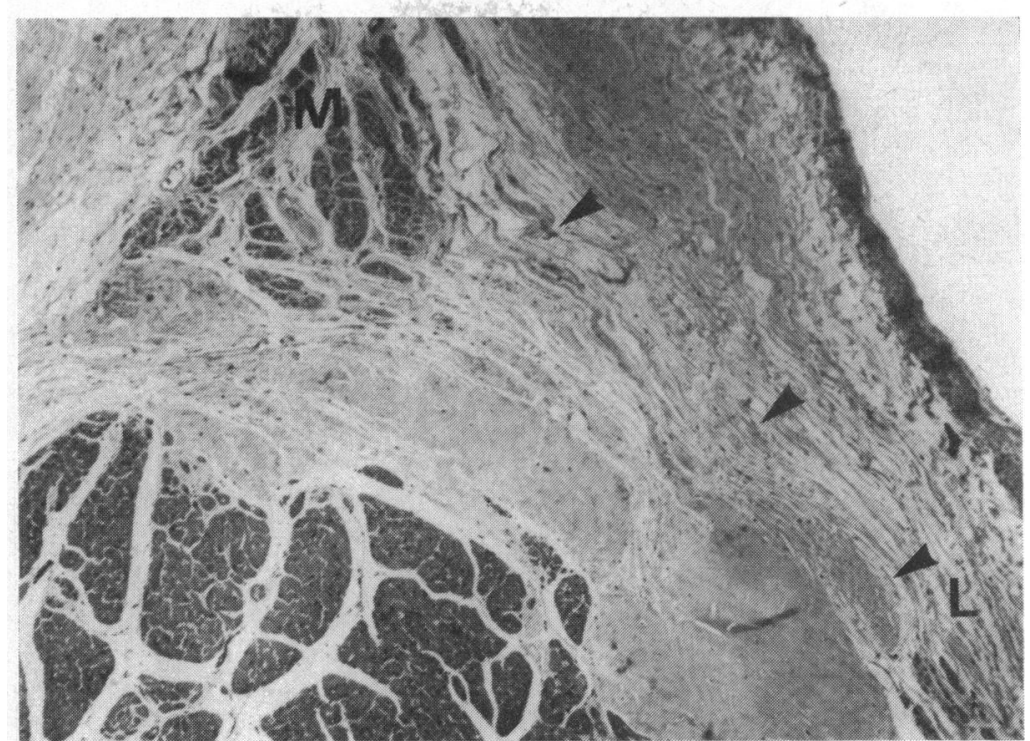

Fig. 3.-The origin of the left bundle-branch in Type $A$ bundle-branch fibrosis. Conduction fibres are lost in the area arrowed. L, left branch; $M$, main bundle. (H. and $\mathrm{E}$. $\times 40$.)

conduction system. No significant coronary atherosclerosis was present with one exception, and in this patient there was an old lateral infarct unrelated to the conduction system. In all patients the nodal artery was normal as were small arteries between 100 and $1000 \mu$ in diameter. Hyaline change in

TABLE

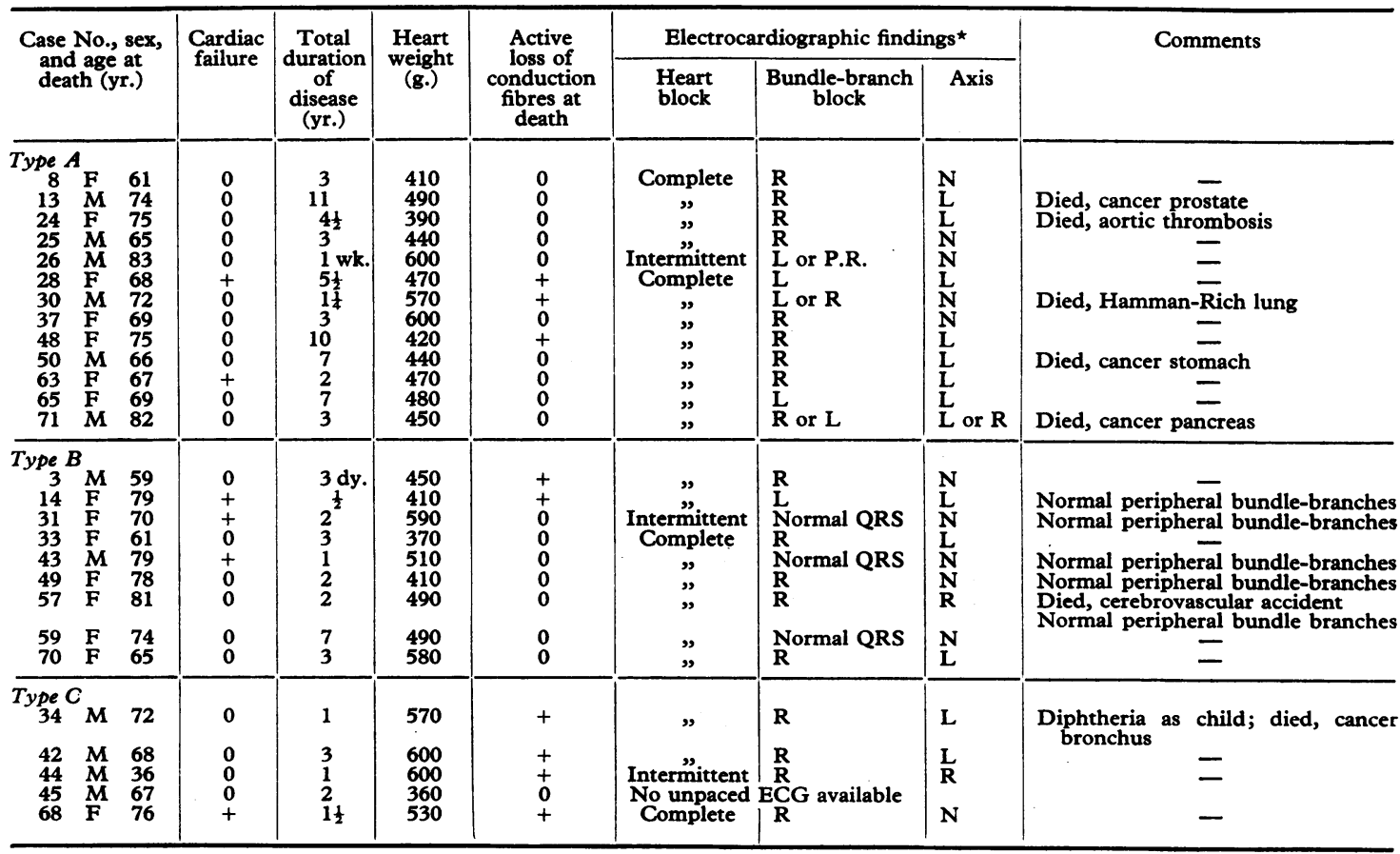

$\star R$, right; $L$, left; $N$, normal. 


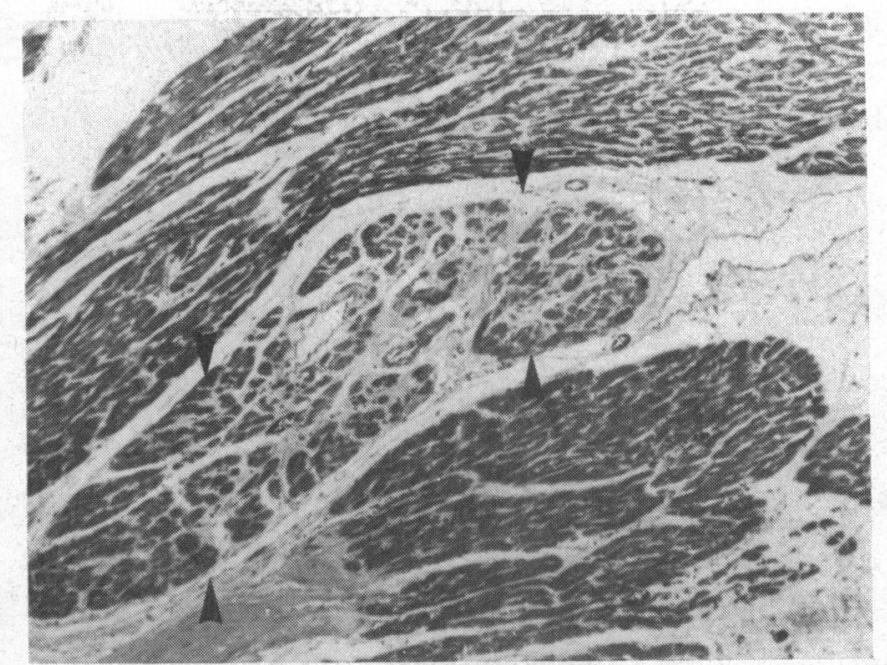

Fig. 4.-The normal right branch (arrowed). The branch is a discrete muscle bundle with conduction fibres that are easily recognized. (H. and E. $\times 40$.)

small arteries below this size is seen equally in the control and disease series and is completely absent in some patients of both groups. Ageing changes including calcification in the collagen of the central fibrous body, valve rings, and upper interventricular septum (Fig. 2) are seen to the same degree in both groups.

\section{Discussion}

Bundle-branch fibrosis is characterized by progressive loss of fibres in the distal conduction system. At the time of death the pathological process in some patients appears to be burned out or static, others still show active loss of conduction fibres. The variability of the site of major loss, and the progressive, perhaps phasic, nature of the disease, lead to a large number of electrocardiographic patterns. A narrow QRS complex with no evidence of bundle-branch block may be seen in type B bundle-branch fibrosis. Lenègre (1964) has reviewed many electrocardiographic patterns seen in bundle-branch fibrosis, and has pointed out that even when right or left bundle-branch block predominates in the cardiogram, the presence of com-

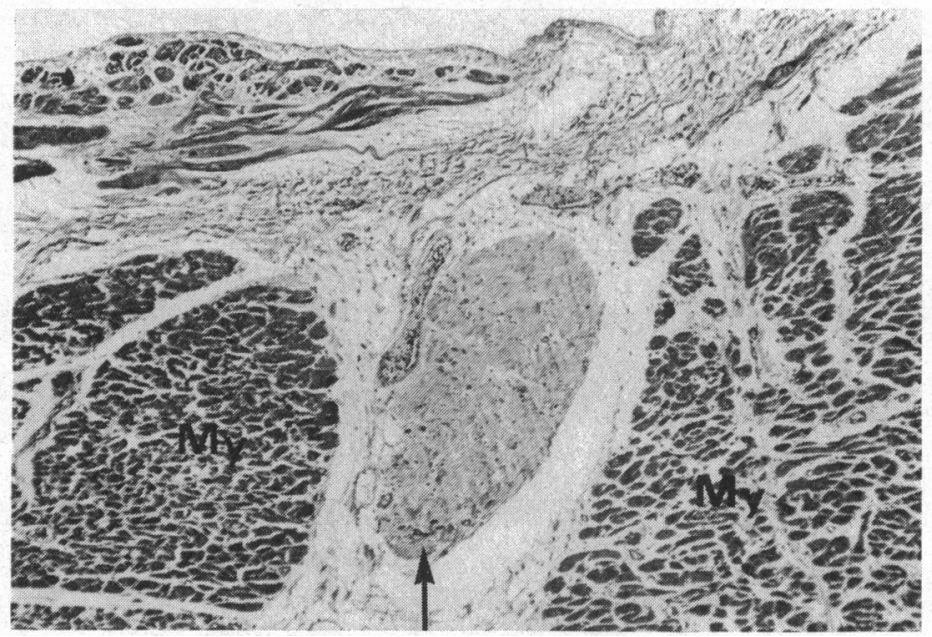

FIG. 5.-The right bundle-branch in bundle-branch fibrosis, type A. The branch is a fibrotic strand containing only isolated conduction fibres (opposite arrow). Adjacent contractile myocardium is normal (My) (H. and E. $\times 40$. 


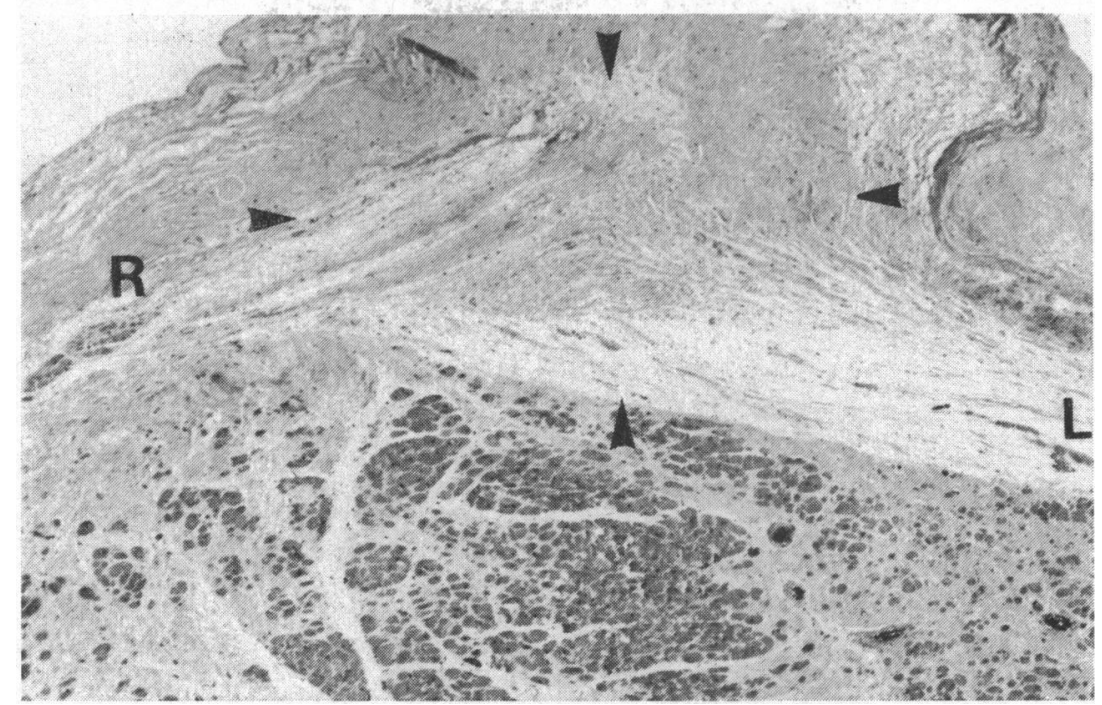

Fis. 6. - The main bundle and origin of the left branch $(\mathrm{L})$ in bundle-branch fibrosis, type $B$. The triangular outline of the main bundle is arrowed. No conduction fibres are present. An occasional conduction fibre persists in the origin of the right (R) and left branch (L). (H. and E. $\times 32$.)

plete heart block must mean lesions in both bundlebranches.

Most patients with bundle-branch fibrosis are elderly, but occasionally young subjects are affected (Table). Lenègre (1964) has shown that abnormalities in the electrocardiogram occur slowly, and the disease is probably initiated many years before complete AV block appears.
The myocardium in bundle-branch fibrosis is abnormal to a varying degree. Considerable cardiac hypertrophy may be present and does not correlate with ventricular rate, length of history, or presence or absence of cardiac failure. Cardiac failure was recorded in six patients, and its occurrence is only partially dependent on a slow rate. Scarring in the myocardium of cases of chronic AV block

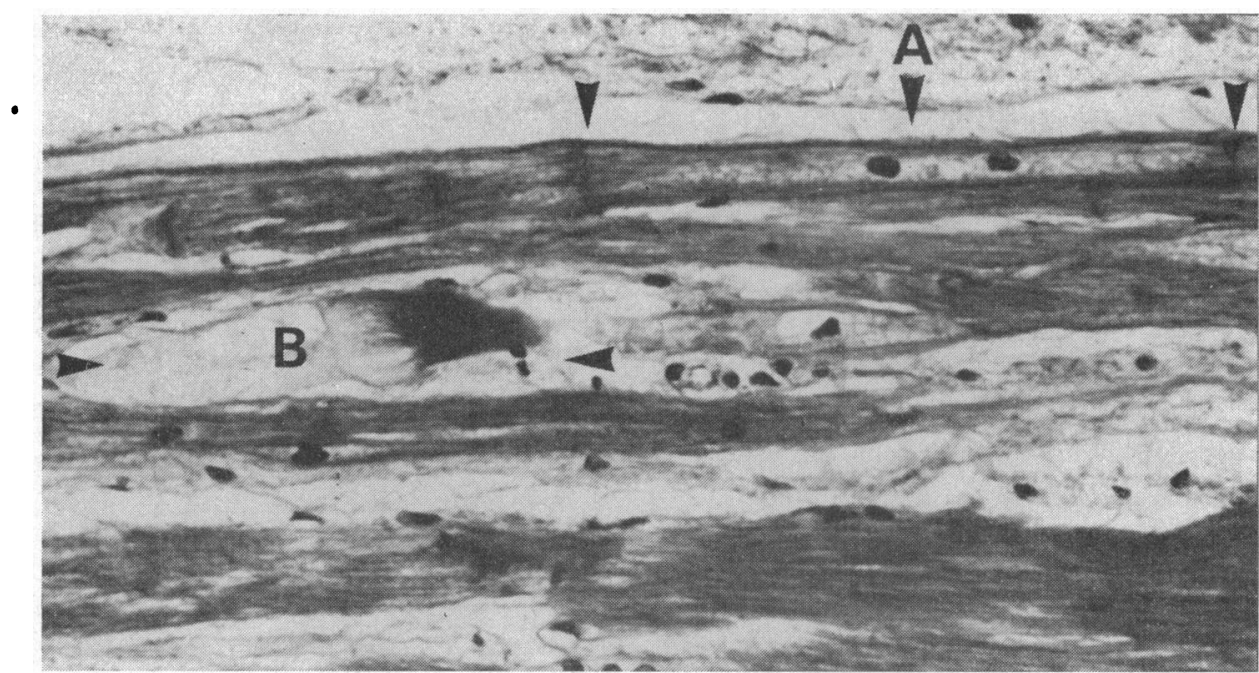

FIG. 7.-A high power view of conduction fibres in the left branch from a case of bundle-branch fibrosis. The majority of fibres are normal, the binucleated fibre with well-marked intercalated disc and vacuolated cytoplasm (A) is a typical conduction fibre. The central fibre (B) is vacuolated with fusion of the myofibrils into a hyaline mass. This is the earliest change recognizable with active loss of conduction fibres. (H. and E. $\times 190$.) 




FIG. 8, 9, 10.-This series illustrates adjacent areas in the right bundle-branch from a case of bundle-branch fibrosis.

FIG. 8.-Acute degenerative changes in all conduction fibres; in some cases small dark cells have appeared with the sarcoplasmic sheath possibly phagocytosing cell remnants (arrowed).The number of conduction fibres is not reduced. (H. and E. $\times$ 150.)

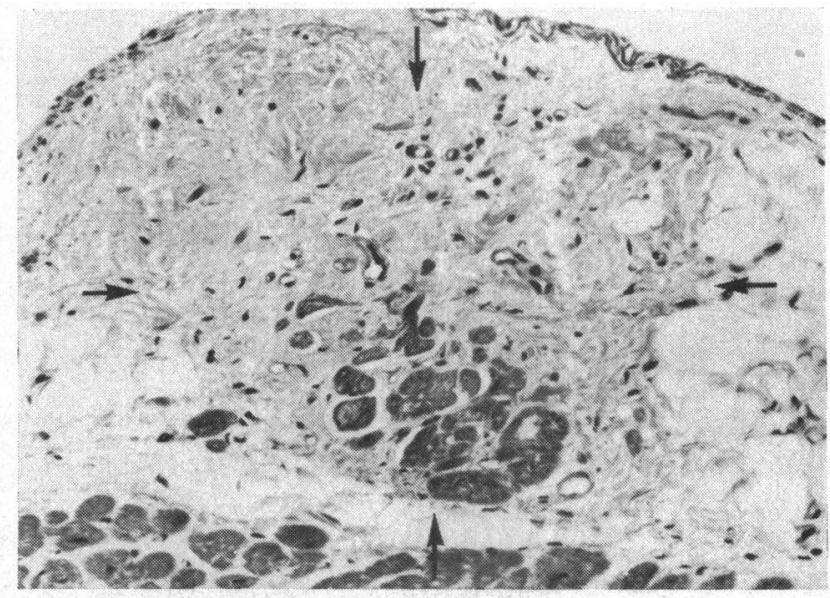

FIG. 9.-In the right branch (arrowed) approximately two-thirds of the conduction fibres are replaced by fibrous tissue. In the lower portion conduction fibres remain. (H. and E. $\times 95$.)

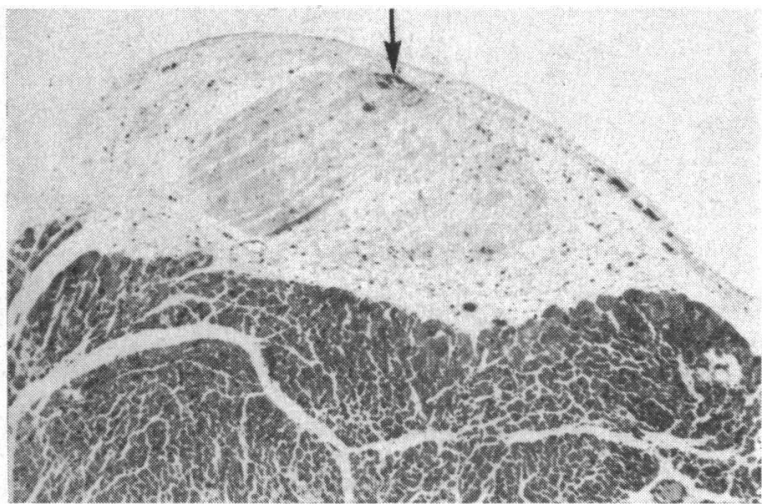

Fig. 10.-Complete loss of conduction fibres is now present apart from 3 fibres (arrowed). (H. and E. $\times 30$.) 
has been measured by Knieriem and Effert (1966) who found a considerable increase over normal hearts. The concept of isolated disease of the conduction system, with an implication of normal contractile function, is therefore only true to a degree. Bundle-branch fibrosis is, however, a disease with a long natural history, and death from coincidental causes is not uncommon (Table).

The selectivity of bundle-branch fibrosis for the conduction system was clearly recognized by Aschoff (1910), but the pathogenesis of such lesions remains controversial. Yater, Cornell, and Claytor (1936) regarded the lesions as anoxic, but failed to explain the sparing of adjacent myocardium. James (1967) has described various types of small vessel disease in conduction disturbances but such changes are not seen in bundle-branch fibrosis. Hyaline arteriosclerosis is common in hearts of this age-group, with and without conduction defects. Since the blood supply of the bundle-branches is that of adjacent myocardium it does not seem possible to relate bundle-branch fibrosis to any vascular disease. Lev (1964) considers bundle-branch fibrosis is related to ageing changes and calcification in the fibrous skeleton of the heart, a process accelerated by hypertension. Such changes are undoubtedly responsible for the normal loss of some conduction fibres in the left branch with increasing age. They may play a part in the development of left bundlebranch block in hypertension but can only explain pure type B bundle-branch fibrosis. Sclerotic ageing changes are not seen in relation to fibrosis of the right branch in its intramyocardial course or to the peripheral conduction network. The hypothesis put forward by Lev and known as "sclerosis of the left side of the cardiac skeleton" can therefore only explain a minority of cases of bundle-branch fibrosis. Cases 14, 31, 43, 49, and 57 (Table) of the present series are examples of this process.

Hudson (1965) has suggested that bundle-branch fibrosis may represent healed myocarditis, and it is known that myocarditis in the acute stage heavily involves the bundle-branches (Lev and Unger, 1955). Previous diphtheria has been implicated (Butler and Levine, 1930), but in the present series of bundle-branch fibrosis no support for this view is found (Table). The conduction system in bundle-branch fibrosis shows no acute inflammatory changes, and if previous myocarditis is implicated, the long latent phase preceding symptoms is difficult to explain. Normal ageing changes, however, lead to some loss of conduction fibres and this, superimposed on a conduction system damaged by previous myocarditis, remains a possible pathogenetic mechanism. Continuing active loss of conduction fibres at the time of death in some cases remains unexplained by all postulated mechanisms.

The only clinical series with sufficient data for comparison is that of Johansson (1966), where 64 of $142(45 \%)$ cases of AV block were considered to be primary. This is similar to the incidence of bundle-branch fibrosis in the present necropsy series $(41 \%)$. The age incidence of both groups shows a peak in the eighth decade. A clinical series of primary heart block will include some patients with unrecognized definitive causes owing to the difficulty of clinical differentiation (Harris et al., 1969), but the majority are likely to be bundle-branch fibrosis.

\section{Conclusion}

The commonest cause of chronic AV block is selective loss of conduction fibres in the bundlebranches at multiple sites. Such loss may be associated with a long history of conduction defect with good contractile function, though all cases have to some degree a pathologically abnormal myocardium, and cardiac failure does occur.

Bundle-branch fibrosis probably has several different aetiologies and pathogenetic mechanisms, and any attempt to explain all cases by one mechanism is invalid. A small proportion are probably due to the exaggerated ageing changes known as sclerosis of the left side of the cardiac skeleton. Some may well represent ageing changes superimposed on a conduction system damaged by previous myocarditis, and in others the morphological changes suggest a primary degenerative process of conduction tissue.

\section{SUMMARY}

A detailed pathological survey of the hearts, including the conduction system, from 27 patients with primary heart block or isolated disease of the conduction system is presented. The disease is characterized by progressive loss of conduction fibres in the bundle-branches with replacement fibrosis; the myocardium is relatively spared. Possible aetiological factors include previous myocarditis, exaggerated ageing changes, and a primary degenerative disease of conduction tissue.

\section{REFERENCES}

Aschoff, L. (1910). Referat über die Herzstörungen in ihren Beziehungen zu den spezifischen Muskelsystemen des Herzens. Verh. dtsch. path. Ges., 14, 3.

Butler, S., and Levine, S. A. (1930). Diphtheria as a cause of late heart-block. Amer. Heart f., 5, 592.

Crawford, T., Dexter, D., and Teare, R. D. (1961). Coronary-artery pathology in sudden death from myocardial ischaemia. A comparison by age-groups. Lancet, $\mathbf{1}_{2}$. 181 . 
Davies, M. J. (1967). A histological study of the conduction system in complete heart block. F. Path. Bact., 94, 351.

Harris, A. M., Davies, M. J., Redwood, D., Leatham, A., and Siddons, H. (1969). The aetiology of chronic heart block. A clinico-pathological correlation in 65 cases. Brit. Heart F., 31, 206.

Hudson, R. E. B. (1965). Cardiovascular Pathology, Vol. 1, p. 111. Arnold, London.

James, T. N. (1967). Pathology of small coronary arteries. Amer. F. Cardiol., 20, 679.

Johansson, B. W. (1966). Complete heart block. A clinical, hemodynamic and pharmacological study in patients with and without an artificial pacemaker. Acta med. Scand., 180, Suppl. 451.

Knieriem, H. J., and Effert, S. (1966). Ubersichten. Morphologische Befunde beim kompletten Herzblock. Klin. Wschr., 44, 349.

Lenègre, J. (1964). Etiology and pathology of bilateral bundle-branch block in relation to complete heart block. Progr. cardiovasc. Dis., 6, 409.

Lev, M. (1964). Anatomic basis for atrioventricular block. Amer. F. Med., 37, 742.

- and Unger, P. N. (1955). The pathology of the conduction system in acquired heart disease. Arch. Path., 60, 502 .

Penton, G. B., Miller, H., and Levine, S. A. (1956). Some clinical features of complete heart block. Circulation, $13,801$.

Portal, R. W., Davies, J. G., Leatham, A., and Siddons, A. H. M. (1962). Artificial pacing for heart-block. Lancet, 2, 1369.

Yater, W. M., Cornell, V. H., and Claytor, T. (1936). Auriculoventricular heart block due to bilateral bundlebranch lesions. Arch. intern. Med., 57, 132.

Zoob, M., and Smith, K. S. (1963). The aetiology of complete heart-block. Brit. med. f., 2, 1149. 